\title{
Regulation of adaptive immune responses by guiding cell movements in the spleen
}

\author{
Lintao Zhao ${ }^{1 \dagger}$, Lina Liut ${ }^{1 \dagger}$, Bo Guo ${ }^{1,2 *}$ and Bo Zhu ${ }^{1 *}$ \\ ${ }^{1}$ Institution of Oncology, Xinqiao Hospital, Third Military Medical University, Chongqing, China, ${ }^{2}$ Department of Microbiology, \\ Third Military Medical University, Chongqing, China
}

\section{OPEN ACCESS}

Edited by:

Amy Rasley,

Lawrence Livermore National

Laboratory, USA

Reviewed by:

Monica E. Embers,

Tulane University, USA

Hridayesh Prakash,

University of Hyderabad, India

*Correspondence:

Bo Zhu and Bo Guo,

Institution of Oncology, Xinqiao

Hospital, Third Military Medical

University, Chongqing 400037, China

b.davis.zhu@gmail.com;

guobomail@gmail.com

tThese authors have contributed equally to this work.

Specialty section:

This article was submitted to Microbial Immunology,

a section of the journal

Frontiers in Microbiology

Received: 14 April 2015

Accepted: 12 June 2015

Published: 25 June 2015

Citation:

Zhao L, Liu L, Guo B and Zhu B (2015) Regulation of adaptive immune responses by guiding cell movements

in the spleen.

Front. Microbiol. 6:645.

doi: 10.3389/fmicb.2015.00645
The spleen combines the innate and adaptive immune systems in a uniquely organized way. The excision of spleen will induce many complications, especially the increased susceptibility to infections. Recent research shows that besides playing roles during the immune responses, the spleen is also an important organ during immunoregulation, which is different from other secondary lymphoid organs. This unique function is mainly realized by modulating cell migration and proliferation in the spleen. This review provides a better understanding of the functions of this complex organ gained from recent studies.

Keywords: spleen, cell migration, immunoregulation, T cells, CCL21

\section{Introduction}

The adaptive immune responses play important roles in anti-infection in vivo and in clearance of exogenous pathogens. The reactivation of these processes necessitates the contact between antigenspecific T/B lymphocytes and antigen-presenting cells carrying corresponding antigens. However, such contact occurs very rarely in vivo (Gretz et al., 1996; Bajenoff et al., 2006; Cesta, 2006) and should be realized in secondary lymphoid organs (SLOs). The spleen is a very important SLO. On a daily basis, a larger count of lymphocytes passes through the spleen than the total count passing through all other SLOs (Bajenoff et al., 2008). The earliest research shows that the excision of the spleen will not largely impact the human immune system. However, recent research shows that this excision will induce many complications, especially the increased susceptibility to infections. These studies indicate that the spleen plays exclusive roles that cannot be fulfilled by other SLOs (Cadili and de Gara, 2008). Moreover, besides playing roles during immune responses, the spleen is also an important organ during immunoregulation, which is different from other SLOs. The spleen could decrease the probability of contact between antigen-specific T/B lymphocytes and antigenpresenting cells carrying corresponding antigens. In addition, it could also induce the extensive accumulation of immunosuppressive cells. Moreover, this characteristic is unique to the spleen among all SLOs. This review focuses on the advances in recent research on the spleen.

\section{Structure of the Spleen}

\section{White Pulp and Red Pulp}

The spleen is composed of white pulp and red pulp. The white pulp consists of $\mathrm{T}$ and $\mathrm{B}$ lymphocytes, which reside in the T-cell zone and the B-cell zone, respectively, rather than mixing together (Figures 1A,B). Besides T cells, the T-cell zone is filled with mesenchymal cells, mainly 
A

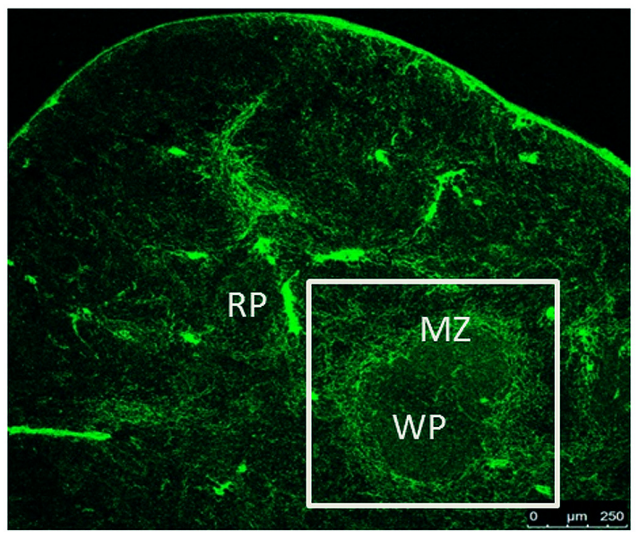

B

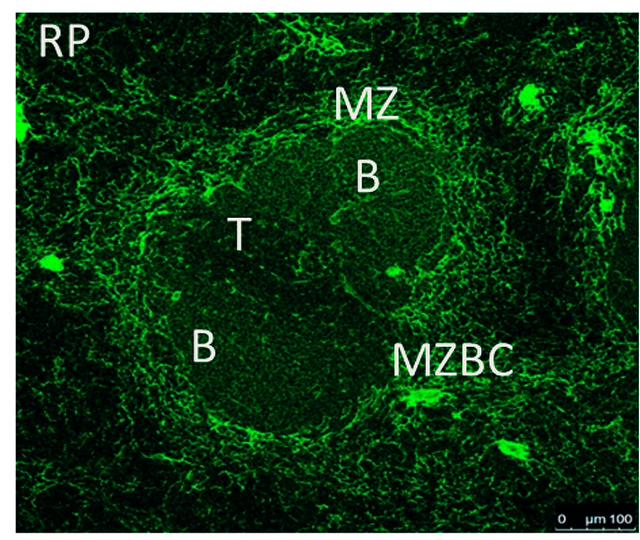

C
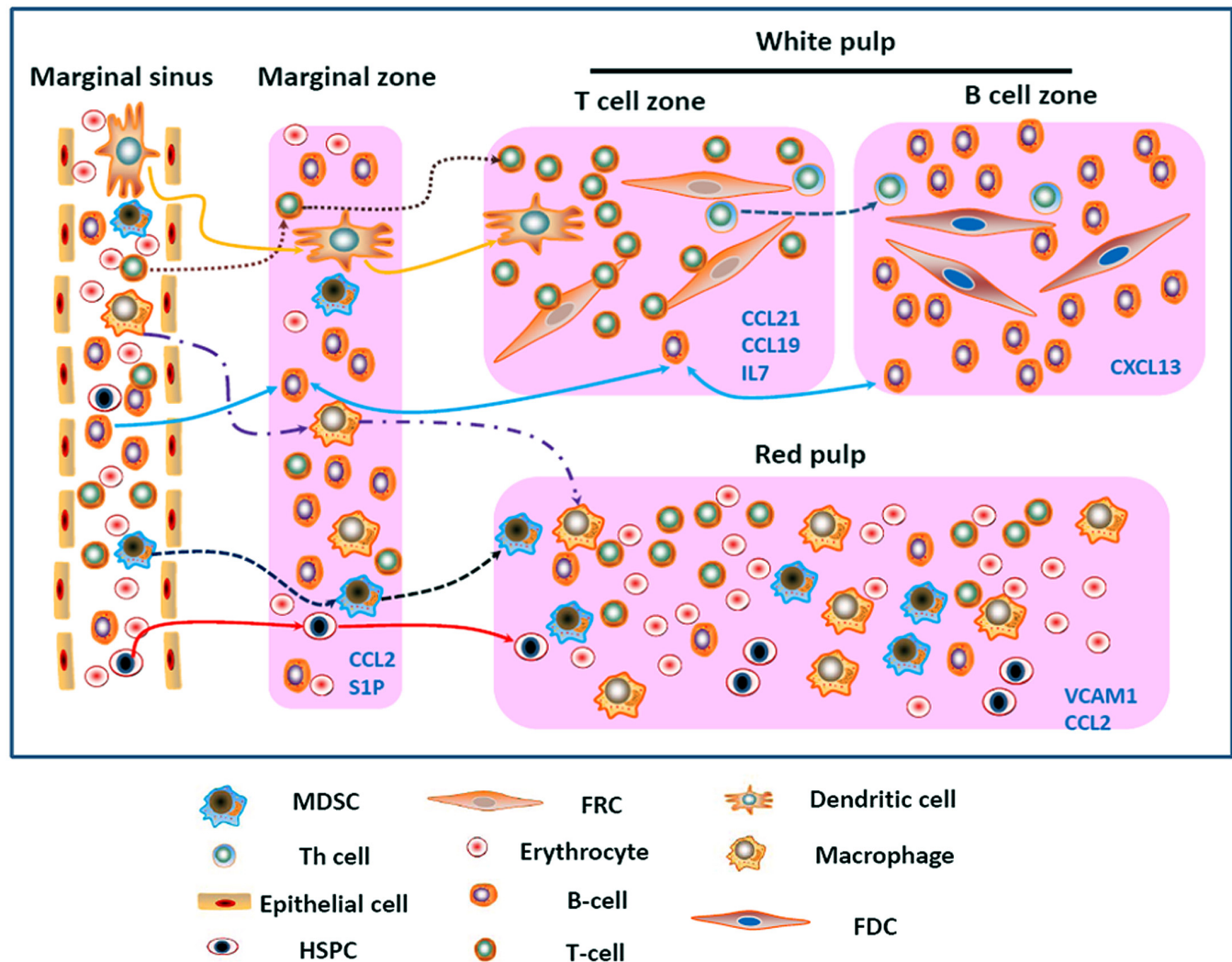

FIGURE 1 | Migration of different types of cells in the spleen.

(A) Spleen cryostat sections from C57BL/6 mice were stained for ER-TR7 (green), and imaged using confocal microscopy (Scale bars: $250 \mu \mathrm{m}$ ); (B) a higher magnification of spleen cryostat sections were observed;

(C) different cell components in the blood enter the marginal sinus, and diffuse to the marginal zone. $T$ and $B$ cells will first arrive at the $T$ cell zone. Then follicular Th cells and B cells would move further to the B cell zone. Moreover, B cells also could shuttle continually between the MZ and follicles. The dendritic cells, after reactivation, could enter the $T$ cell zone. MDSCs could be attracted by CCL2 and retained in the MZ and red pulp. Besides, adhesion molecule VCAM-1in red pulp could retain bone marrow HSPCs. fibroblastic reticular cells (FRCs), while the mesenchymal components of the B-cell zone are mainly fibroblastic dendritic cells (FDCs; Turley et al., 2010; den Haan et al., 2012). In addition, the red pulp which surrounds the white pulp is a loose web-like structure constituted by fibrous tissues. The aging red blood cells (RBCs) will be cleared away from this structure. The spleen with rich blood supply is an organ constituted by blood vessels encircling different branches. The blood after entering the spleen will pass through different levels of artery branch vessels. Finally, a part of the blood mingles into the marginal sinus (between the marginal zone and the white pulp); the other part directly enters the blood sinus in the red pulp and finally flows 
outside the spleen through the splenic veins. Specifically, the lymphocytes after entering the marginal sinus can directionally migrate to the surroundings of the central artery in the arterial terminal branches (Mebius and Kraal, 2005; Cesta, 2006) to form white pulp. On the contrary, other cell components will flow along with the blood into the red pulp. The red pulp contains abundant phagocytes, which will clear away the old RBCs and the pathogenic microorganism (den Haan et al., 2012).

\section{The Marginal Zone}

This zone resides between the splenic white pulp and red pulp. This structure is unique among all splenic SLOs (Figure 1B). In this zone, abundant macrophages termed marginal-zone macrophages and marginal-zone metallophilic macrophages (MMMs), as well as dendritic cells (DCs) designated as marginalzone DCs, and B cells (Bajenoff et al., 2008) pathogenic microorganism and aging cells will be largely swallowed by the macrophages, while the DCs will ingest the antigens. Moreover, the lymphocytes flowing into the blood will stay for a short period before entering the white pulp. The lymphocyte and the reactivated antigen-presenting cells, after arriving at the marginal zone, will enter the white pulp along specific routes, rather than randomly. In the MOMA-1-positive marginal zone, the macrophages will constitute a ring-like structure surrounding the white pulp, which helps to fully isolate the white pulp and the marginal zone. However, this ring-like structure is not perfect, since it has a gap. These cells are called marginal-zone B cells (MZBCs). This gap is a channel where various cells enter the white pulp. Interestingly, MZBCs only exist around the T-cell zone in the white pulp, rather than the B-cell zone (Bajenoff et al., 2008). These facts increase the probability of contact between the antigen-specific T/B lymphocytes and the antigenpresenting cells carrying corresponding antigens. For example, the antigen-presenting cells after activation would migrate to in the T-cell zone and retain there. The antigen-specific $\mathrm{T}$ cells migrate along the specific track into and out of the T-cell zone. These abilities allow $\mathrm{T}$ cells to move throughout the entire T-cell zone. As a result, the probability of contact between the antigenspecific $\mathrm{T}$ lymphocytes and the antigen- presenting cells carrying corresponding antigens could be maximized. On the contrary, this probability would be reduced greatly if the T cells can migrate into and out of the splenic T-cell zone randomly. Moreover, the marginal zone also contains a specific B cell subzone. MZBCs which reside between the marginal zone and the red pulp can capture antigens carried in the blood via complement receptors, and promote both T-cell-independent and -dependent immune responses.

\section{Conduit System}

There is a special harrow 3D web-like structure in the SLOs, which is constituted by FRCs as well as the FRCssecreted extracellular matrix (ECM). These FRCs mainly express podoplanin (gp38), but not the lymphatic and blood endothelial cell marker: platelet endothelial cell adhesion molecule (PECAM, CD31; Mueller and Germain, 2009; Malhotra et al., 2013). The FRCs wrap up a harrow microtubule system, constituted by the FRCs-secreted ECMs. The microtubule system in the SLOs can be detected by ER-TR7 (Alvarenga and Marti, 2014). The diameter of the microtubules is usually $4-5 \mathrm{~nm}$, which are only accessible to molecules smaller than $70 \mathrm{KD}$. The distributive characteristics of these microtubules in the lymph nodes (LNs) have been thoroughly studied, but those in the spleen are unclear. It is deduced that one end of a microtubule is located in the B-cell zone and particularly the T-cell zone, while the other end is located in the red pulp or the marginal zone. With the presence of these microtubules in the spleen, the micro- molecular antigens can rapidly pass from the blood to the T-cell zone. Though these microtubules are distributed rarely in the B-cell zone, conduits may also serve as a pathway for low-molecular-weight antigens to reach follicles and facilitate $B$ cell responses (Stranford and Ruddle, 2009).

\section{Directed Migration of Different Cells in the Spleen}

The directed migration of different cell components is regulated by chemokines (Table 1), especially CCL21, CCL19, and CXCL13. The FRCs in the T-cell zone secrete CCL21 and CCL19, while after binding to the receptor CCR7 in T cells, they can chemoattract T cells (Ueha et al., 2011; Ugel et al., 2012). The FDCs in the B-cell zone secrete CXCL13, which functions by acting on its receptor CXCR5. CXCL13 guides B cells and follicular $\mathrm{T}$ helper (Th) cells into the $\mathrm{B}$ cell zone. The critical roles of these homeostatic chemokines in attracting cells into lymphoid organs and in initiating the antigen-specific responses are well-established (Mueller et al., 2007).

TABLE 1 | Main chemokines and molecules in the spleen.

\begin{tabular}{|c|c|c|c|c|c|c|c|}
\hline $\begin{array}{l}\text { Chemokines } \\
\text { and molecules }\end{array}$ & Receptor & Target cells & $\begin{array}{l}\text { Expression } \\
\text { regions }\end{array}$ & $\begin{array}{l}\text { Promoting } \\
\text { production }\end{array}$ & $\begin{array}{l}\text { Inhibiting } \\
\text { production }\end{array}$ & Producing cells & Function \\
\hline CCL21 & CCR7 & T cells; DCs & T cell zone & LTs and TNFs & IFN-r & Mainly by FRCS & Attracting T cells \\
\hline CCL19 & CCR7 & T cells; DCs & T cell zone & LTs and TNFs & IFN-r & Mainly by FRCS & Attracting $T$ cells \\
\hline CXCL13 & CCR5 & B cells; Th cells & B cell zone & LT-B & IFN-r & Mainly by FDCS & Attracting B cells \\
\hline $\mathrm{IL} 7$ & IL7R & $\mathrm{T}$ cells & T cell zone & LT-B & IFN-r and TGF- $\beta 1$ & Mainly by FRCS & T cell homeostasis \\
\hline CCL2 & CCR2 & MDSCs & $\begin{array}{l}\text { Margin zone; } \\
\text { red pulp }\end{array}$ & Unknown & Unknown & Nestin $^{+}$splenocytes & Attracting MDSCs \\
\hline S1P & S1PR1; S1PR3 & B cells & Margin zone & Unknown & Unknown & LyVE-1+ cells & Attracting B cells \\
\hline VCAM-1 & VLA-4 & HPSCs & Red pulp & Unknown & Unknown & VCAM-1+ macrophages & Attracting HPSCs \\
\hline
\end{tabular}


First, the different cell components in the blood will enter the marginal sinus through all levels of vascular branches, and thereby diffuse to the marginal zone. In this zone, the $\mathrm{T}$ and $\mathrm{B}$ cells will first adhere to the ER-TR7-positive fiberweb-like structure and migrate along the fasciculus in an oriented way. They first arrive at the marginal zone bridging channels (MZBCs) and then at the T-cell zone. The differentiation of $\mathrm{T}$ cells into follicular $\mathrm{T}$ helper (Th) cells will induce expression of CXCR5 in Th cells. Then Th cells and $\mathrm{B}$ cells would move further until arrive at the B-cell zone (Pereira et al., 2010).

Moreover, B cells express the chemokine receptor CXCR5 and thus can respond to the follicular attracting activity mediated by its ligand CXCL13. However, B cells could also overcome such activity by largely expressing the sphingosine-1 phosphate (S1P) receptors-1 and -3 (S1PR1, S1PR3). The binding of the lysophospholipid S1P which produced by LyVE-1 $1^{+}$cells to these receptors will trigger a chemotactic response and promote the accumulation of $B$ cells in the marginal zone and red pulp which contains higher concentrations of S1P. Nevertheless, intravital microscopy studies indicate that MZBCs shuttle continually between the marginal zone and follicles. The mechanisms that control such oscillatory migration involves transient S1PR1 desensitization (for migration from the marginal zone into the follicles), followed by S1PR1 resensitization (for migration back to the marginal zone; Mehta et al., 2014). Moreover, the marginal zone is also permanently planted with many DCs, which, after digestion and reactivation with antigens, can express CCR7. Through the movement orbit of $\mathrm{T}$ cells, they could enter the $\mathrm{T}$-cell zone and reactivate the antigen-specific $\mathrm{T}$ cells (Turley et al., 2010).

Just as mentioned before, except some kinds of cells (e.g., $T$ cells, B cells, and DCs), other cells will flow along the blood stream into the red pulp. Myeloid-derived suppressor cells (MDSCs) which express CCR2 could be attracted by CCL2 and retain in the red pulp. Besides, bone marrow hematopoietic stem/progenitor cells (HSPCs) also could retain in the red pulp by vascular cell adhesion molecule 1 (VCAM-1) ${ }^{+}$macrophages, which use the adhesion molecule VCAM-1 to retain HSPCs through its receptor - very late antigen 4 (VLA-4; Bronte and
Pittet, 2013). In certain condition, a large amount of MDSCs or HSPCs could accumulate in the red pulp and influence the immune response. In the end, rest of the cells would flow out of the spleen along the blood stream (Figure 1C).

\section{Regulation of Chemokine Secretion}

The expressions of CCL21 and CCL19 by FRCs in the splenic $\mathrm{T}$ cell zone and LNs facilitate the effective interaction between DCs and T cells (Luther et al., 2011). The secretion of these chemokines in SLOs is not constant, but can be regulated by different molecules. Firstly, previous research shows that the mesenchymal cells of SLOs require continuous signals from many molecules, so as to maintain their secretion of CCL21 and 19. The most-studied molecules are the tumor necrosis factor (TNF) family members. For example: LTs and TNFs are among such signaling molecules (Klaus et al., 1980; Schneider et al., 2004; Zhao et al., 2015). The deletion of these factors will induce the down-regulation of CCL21 and CCL19. However, the redundancy in TNF/LT ligand-receptor interactions complicates the understanding about the distinct contribution of particular ligand to the complex phenotype of TNF/LT-deficient mice (Tumanov et al., 2003; Zhao et al., 2014). In addition, these maintaining factors are mainly secreted by lymphocytes (Sixt et al., 2005; Zhao et al., 2014). As reported, the deletion of $\mathrm{T}$ cells will also lead to the significantly down-regulated secretory volumes of CCL19 and CCL21, and the expression levels of these chemokines can be recovered after the transfusion of $\mathrm{T}$ cells. Even the maintaining effects of these factors have not changed, some molecules also could directly down-regulate the expressions of CCL21 and CCL19. For instance, upon infection, the reactivated $\mathrm{T}$ cells will secrete abundant IFN-r, which will induce the down-regulated expressions of CCL21 and CCL19, and thereby down-regulate the immune response of $\mathrm{T}$ cells upon the next infection (Mueller et al., 2007; Li et al., 2014). In addition, expressions of CCL21 and CCL19 were also reduced in the spleen of Inflammatory Melanomas, but the reasons were not very clear (Soudja et al., 2011).

TABLE 2 | Effects of chemokine disorders on splenic microenvironments.

\begin{tabular}{|c|c|c|c|c|c|c|c|c|}
\hline \multirow{2}{*}{$\begin{array}{l}\text { Spleen } \\
\text { region }\end{array}$} & \multicolumn{2}{|c|}{ Marginal zone } & \multicolumn{2}{|c|}{ T cell zone } & \multicolumn{2}{|c|}{ B cell zone } & \multicolumn{2}{|c|}{ Red pulp } \\
\hline & $\begin{array}{l}\text { Chemokine } \\
\text { change }\end{array}$ & Effect & $\begin{array}{l}\text { Chemokine } \\
\text { change }\end{array}$ & Effect & $\begin{array}{l}\text { Chemokine } \\
\text { change }\end{array}$ & Effect & $\begin{array}{l}\text { Chemokine } \\
\text { change }\end{array}$ & Effect \\
\hline Infection & Unknown & Unknown & $\begin{array}{l}\text { CCL21 } \\
\text { CCL19 }\end{array}$ & $\begin{array}{l}\text { Inhibiting migration of } \\
T \text { cells to } T \text { cell zone }\end{array}$ & CXCL13 $\downarrow$ & $\begin{array}{l}\text { Inhibiting migration of } \\
\mathrm{B} \text { cells to B cell zone }\end{array}$ & Unknown & Unknown \\
\hline Tumor & CCL2个 & $\begin{array}{l}\text { MDSCs } \\
\text { accumulation }\end{array}$ & Unknown & Unknown & Unknown & Unknown & CCL2个 & MDSCs accumulation \\
\hline Anemia & Unknown & Unknown & Unknown & Unknown & Unknown & Unknown & Unknown & $\begin{array}{l}\text { CD71+erythroid progenitor } \\
\text { cells accumulation }\end{array}$ \\
\hline HIV & Unknown & Unknown & $\| \mathrm{L} 7 \downarrow$ & T cells depletion & Unknown & Unknown & Unknown & Unknown \\
\hline $\begin{array}{l}\text { Inflammatory } \\
\text { melanomas }\end{array}$ & $\mathrm{CCL} 2 \uparrow$ & $\begin{array}{l}\text { MDSCs } \\
\text { accumulation }\end{array}$ & $\begin{array}{l}\text { CCL21 } \\
\text { CCL19 }\end{array}$ & $\begin{array}{l}\text { Inhibiting migration of } \\
T \text { cells to } T \text { cell zone }\end{array}$ & Unknown & Unknown & $\mathrm{CCL} 2 \uparrow$ & MDSCs accumulation \\
\hline
\end{tabular}


The chemokine CXCL13 is made broadly by follicular DCs (FDCs). Regulation of CXCL13 is much like the pattern of CCL21 and CCL19. Expression of CXCL13 is dependent on the cytokine lymphotoxin (LT)-B and a positive feedback loop involving CXCR5-mediated induction of LT-B expression by B cells contributes to maximal CXCL13 production and maturation of the FDC network. In addition, production of IFN-r also inhibits the expressions of CXCL13 which could inhibit B cells movement (Li et al., 2014).

Besides CCL21 and CCL19, the stromal cells FRCs can also secrete IL7 and participate in maintaining the homeostasis of T cells (Zhao et al., 2014). This secretion is mainly regulated by LT-B. The LT-B in the T-cell zone of SLOs is mainly secreted by $\mathrm{T}$ cells. Among acquired immune deficiency syndrome (AIDS) patients, the reduced count of $\mathrm{T}$ cells in SLOs will lead to the reduced secretion of LT-B and thus impact the secretion of IL7 (Sixt et al., 2005). Previous researches show that T regulatory cells could promote the procollagen production and subsequent deposition as fibrils via the TGF- $\beta 1$ signaling pathway and chitinase 3-like-1 activity in fibroblasts in lymphoid tissues from human immunodeficiency virus (HIV)-1-infected patients. Collagen deposition restricts the access of $\mathrm{T}$ cell to the survival factor IL-7 on the FRC network, resulting in apoptosis and depletion of $\mathrm{T}$ cells, which in turn removes a major source of lymphotoxin- $\beta$ (Fry and Mackall, 2005; Levy et al., 2009; Zeng et al., 2011, 2012).

Production of CCL2, which could induce a large amount of accumulation of MDSCs through CCR2, is strongly increased in tumor-bearing mice, and nestin ${ }^{+}$splenocytes clearly participate in the increase in chemokine production in tumor- bearing hosts. These cells were rarely detectable in the spleen of tumor-free mice (Ugel et al., 2012).

\section{The Role of Blood Flow}

Moreover, though not confirmed, we speculate that the blood flow rate in the spleen will also affect the speeds of different cell components entering the spleen. The reason is that when the expressions of various chemokines are unchanged, the blood flow rate will directly determine the speeds of different cell components entering the spleen, thereby impacting the speed of immune response. In clinic, the key factors that induce the changes of blood flow rate in the spleen are the blood pressure and the size of the spleen. When other conditions are not changed, the blood flow will change with the variation of blood pressure. When the blood pressure is unchanged, the increase of spleen size will accelerate the blood flow in the spleen. This may also explain why the spleen expands upon the onset of chronic infection in many patients. Therefore, the pathogen clearance rate can be improved by increasing the blood flow in the spleen.

\section{Immunosuppressive Cells}

Myeloid-derived suppressor cells as immature myeloid cells are the precursors of DCs, macrophages, and/or granulocytes.
Previous research shows that it is mainly distributed in the marginal zone and red pulp of the spleen (Ugel et al., 2012). The contents of immunosuppressive substances vary among MDSCs, with different populations containing arginase, inducible NO synthase, and/or additional ROS. Their accumulation has been documented in most patients and mice with cancer, which is induced by various factors produced by tumor cells and/or host cells in the tumor microenvironment. These substances will also accumulate in response to bacterial or parasitic infection, chemotherapy, experimentally induced autoimmunity, and stress. MDSCs are considered as a major contributor to the profound immune dysfunction of most patients with sizable tumor burdens (Ostrand-Rosenberg et al., 2012; Ugel et al., 2012). Previous research shows that these cells express CCR2, whose ligand is CCL2. Accumulation of MDSCs in the spleen could cause by increased production of CCL2 (Table 2). However, recent researches show that these cells also could proliferate in the spleen in certain condition. This also play an important role in the accumulation of these cells.

Moreover, as reported, bone marrow HSPCs can enter circulation in the steady-state. If conditions permit, the circulating HSPCs will produce lineage-descendant cells outside the bone marrow. This so-called extramedullary hematopoiesis occurs predominantly in the liver in the developing embryo, but also in adult tissues including the spleen. Red pulp vascular cell adhesion molecule 1 (VCAM-1) $^{+}$macrophages are essential to extramedullary myelopoiesis because these macrophages use the adhesion molecule VCAM-1 to retain HSPCs in the spleen red pulp. Indeed, under specific disease conditions, splenic HSPCs will profoundly expand. Splenic hematopoiesis has been reported in animal models of several diseases, including cancer, atherosclerosis myocardial infarction, and colitis (Cortez-Retamozo et al., 2012; Bronte and Pittet, 2013). However, there is no report whether these cells are active during immunoregulation. Nevertheless, recent research shows that $\mathrm{CD} 71^{+}$erythroid progenitor cells are physiologically enriched in neonatal mice, and $\mathrm{CD}_{71}{ }^{+}$cells are produced after extensive proliferation and differentiation of HSPCs. These cells show immunosuppressive properties which could inhibit microphage function (Table 2). Specifically, the count of $\mathrm{CD}_{7} 1^{+}$erythroid cells in the spleens of new-born mice is significantly larger than that in mature mice. Moreover, Neonatal $\mathrm{CD}_{7}{ }^{+}$cells express the enzyme arginase- 2 and play important roles in the immunosuppression of new-born mice, which are different from mature mice (Elahi et al., 2013).

\section{Conclusion}

The spleen undertakes important roles in SLOs, such as clearance of antigens from the blood, and generation of specific immune responses. Moreover, the spleen plays important roles in regulation of immune responses. Many functions of the spleen are unique and irreplaceable among other SLOs. Finally, more studies on the spleen are needed before dismissing its importance. 


\section{References}

Alvarenga, H. G., and Marti, L. (2014). Multifunctional roles of reticular fibroblastic cells: more than meets the eye? J. Immunol. Res. 2014, 402038402038. doi: 10.1155/2014/402038

Bajenoff, M., Egen, J. G., Koo, L. Y., Laugier, J. P., Brau, F., Glaichenhaus, N., et al. (2006). Stromal cell networks regulate lymphocyte entry, migration, and territoriality in lymph nodes. Immunity 25, 989-1001. doi: 10.1016/j.immuni.2006.10.011

Bajenoff, M., Glaichenhaus, N., and Germain, R. N. (2008). Fibroblastic reticular cells guide $\mathrm{T}$ lymphocyte entry into and migration within the splenic $\mathrm{T}$ cell zone. J. Immunol. 181, 3947-3954. doi: 10.4049/jimmunol.181.6.3947

Bronte, V., and Pittet, M. J. (2013). The spleen in local and systemic regulation of immunity. Immunity 39, 806-818. doi: 10.1016/j.immuni.2013.10.010

Cadili, A., and de Gara, C. (2008). Complications of splenectomy. Am. J. Med. 121, 371-375. doi: 10.1016/j.amjmed.2008.02.014

Cesta, M. F. (2006). Normal structure, function, and histology of the spleen. Toxicol. Pathol. 34, 455-465. doi: 10.1080/01926230600867743

Cortez-Retamozo, V., Etzrodt, M., Newton, A., Rauch, P. J., Chudnovskiy, A., Berger, C., et al. (2012). Origins of tumor-associated macrophages and neutrophils. Proc. Natl. Acad. Sci. U.S.A. 109, 2491-2496. doi: 10.1073/pnas.1113744109

den Haan, J. M., Mebius, R. E., and Kraal, G. (2012). Stromal cells of the mouse spleen. Front. Immunol. 3:201. doi: 10.3389/fimmu.2012.00201

Elahi, S., Ertelt, J. M., Kinder, J. M., Jiang, T. T., Zhang, X., Xin, L., et al. (2013). Immunosuppressive CD71(+) erythroid cells compromise neonatal host defence against infection. Nature 504, 158-162. doi: 10.1038/nature 12675

Fry, T. J., and Mackall, C. L. (2005). The many faces of IL-7: from lymphopoiesis to peripheral T cell maintenance. J. Immunol. 174, 6571-6576. doi: 10.4049/jimmunol.174.11.6571

Gretz, J. E., Kaldjian, E. P., Anderson, A. O., and Shaw, S. (1996). Sophisticated strategies for information encounter in the lymph node: the reticular network as a conduit of soluble information and a highway for cell traffic. J. Immunol. $157,495-499$.

Klaus, G. G., Humphrey, J. H., Kunkl, A., and Dongworth, D. W. (1980). The follicular dendritic cell: its role in antigen presentation in the generation of immunological memory. Immunol. Rev. 53, 3-28. doi: 10.1111/j.1600065X.1980.tb01038.x

Levy, Y., Lacabaratz, C., Weiss, L., Viard, J. -P., Goujard, C., Lelievre, J. -D., et al. (2009). Enhanced T cell recovery in HIV-1-infected adults through IL-7 treatment. J. Clin. Investig. 119, 997-1007. doi: 10.1172/jci38052

Li, C. R., Jiang, S., Liu, S. Q., Lykken, E., Zhao, L. T., Sevilla, J., et al. (2014). MeCP2 enforces Foxp3 expression to promote regulatory $\mathrm{T}$ cells' resilience to inflammation. Proc. Natl. Acad. Sci. U.S.A. 111, E2807-E2816. doi: 10.1073/pnas.1401505111

Luther, S. A., Vogt, T. K., and Siegert, S. (2011). Guiding blind T cells and dendritic cells: a closer look at fibroblastic reticular cells found within lymph node $\mathrm{T}$ zones. Immunol. Lett. 138, 9-11. doi: 10.1016/j.imlet.2011.02.006

Malhotra, D., Fletcher, A. L., and Turley, S. J. (2013). Stromal and hematopoietic cells in secondary lymphoid organs: partners in immunity. Immunol. Rev. 251, 160-176. doi: 10.1111/imr.12023

Mebius, R. E., and Kraal, G. (2005). Structure and function of the spleen. Nat. Rev. Immunol. 5, 606-616. doi: 10.1038/nril669

Mehta, G., Shiozawa, Y., and Taichman, R. (2014). "Hematopoietic stem cells and their niches," in Biomaterials and Regenerative Medicine, ed. P. X. Ma (Cambridge: Cambridge University Press), 44-63.

Mueller, S. N., and Germain, R. N. (2009). Stromal cell contributions to the homeostasis and functionality of the immune system. Nat. Rev. Immunol. 9, 618-629.

Mueller, S. N., Hosiawa-Meagher, K. A., Konieczny, B. T., Sullivan, B. M., Bachmann, M. F., Locksley, R. M., et al. (2007). Regulation of homeostatic chemokine expression and cell trafficking during immune responses. Science 317, 670-674. doi: 10.1126/science.1144830

Ostrand-Rosenberg, S., Sinha, P., Beury, D. W., and Clements, V. K. (2012). Crosstalk between myeloid-derived suppressor cells (MDSC), macrophages, and dendritic cells enhances tumor-induced immune suppression. Semin. Cancer Biol. 22, 275-281. doi: 10.1016/j.semcancer.2012.01.011

Pereira, J. P., Kelly, L. M., and Cyster, J. G. (2010). Finding the right niche: B-cell migration in the early phases of T-dependent antibody responses. Int. Immunol. 22, 413-419. doi: 10.1093/intimm/dxq047

Schneider, K., Potter, K. G., and Ware, C. F. (2004). Lymphotoxin and LIGHT signaling pathways and target genes. Immunol. Rev. 202, 49-66. doi: $10.1111 / \mathrm{j} .0105-2896.2004 .00206 . \mathrm{x}$

Sixt, M., Kanazawa, N., Seig, M., Samson, T., Roos, G., Reinhardt, D. P., et al. (2005). The conduit system transports soluble antigens from the afferent lymph to resident dendritic cells in the T cell area of the lymph node. Immunity 22, 19-29. doi: 10.1016/j.immuni.2004.11.013

Soudja, S. M., Henri, S., Mello, M., Chasson, L., Mas, A., Wehbe, M., et al. (2011). Disrupted lymph node and splenic stroma in mice with induced inflammatory melanomas is associated with impaired recruitment of $\mathrm{T}$ and dendritic cells. PLoS ONE 6:e22639. doi: 10.1371/journal.pone.0022639

Stranford, S., and Ruddle, N. H. (2009). Follicular dendritic cells, conduits, lymphatic vessels, and high endothelial venules in tertiary lymphoid organs: parallels with lymph node stroma. Front. Immunol. 3:350. doi: 10.3389/fimmu.2012.00350

Tumanov, A. V., Kuprash, D. V., and Nedospasov, S. A. (2003). The role of lymphotoxin in development and maintenance of secondary lymphoid tissues. Cytokine Growth Factor Rev. 14, 275-288. doi: 10.1016/S1359-6101(03)00026-1

Turley, S. J., Fletcher, A. L., and Elpek, K. G. (2010). The stromal and haematopoietic antigen-presenting cells that reside in secondary lymphoid organs. Nat. Rev. Immunol. 10, 813-825. doi: 10.1038/nri2886

Ueha, S., Shand, F. H., and Matsushima, K. (2011). Myeloid cell population dynamics in healthy and tumor-bearing mice. Int. Immunopharmacol. 11, 783-788. doi: 10.1016/j.intimp.2011.03.003

Ugel, S., Peranzoni, E., Desantis, G., Chioda, M., Walter, S., Weinschenk, T., et al. (2012). Immune tolerance to tumor antigens occurs in a specialized environment of the spleen. Cell Rep. 2, 628-639. doi: 10.1016/j.celrep.2012.08.006

Zeng, M., Paiardini, M., Engram, J. C., Beilman, G. J., Chipman, J. G., Schacker, T. W., et al. (2012). Critical role of CD4 T cells in maintaining lymphoid tissue structure for immune cell homeostasis and reconstitution. Blood 120, 1856-1867. doi: 10.1182/blood-2012-03-418624

Zeng, M., Smith, A. J., Wietgrefe, S. W., Southern, P. J., Schacker, T. W., Reilly, C. S., et al. (2011). Cumulative mechanisms of lymphoid tissue fibrosis and $\mathrm{T}$ cell depletion in HIV-1 and SIV infections. J. Clin. Investig. 121, 998-1008. doi: 10.1172/JCI 45157

Zhao, L., Chen, J., Liu, L., Gao, J., Guo, B., and Zhu, B. (2015). Essential role of TNF-alpha in development of spleen fibroblastic reticular cells. Cell. Immunol. 293, 130-136. doi: 10.1016/j.cellimm.2015.01.006

Zhao, L., Liu, L., Gao, J., Yang, Y., Hu, C., Guo, B., et al. (2014). T lymphocytes maintain structure and function of fibroblastic reticular cells via lymphotoxin (LT)-B. BMC Immunol. 15:33. doi: 10.1186/s12865-014-0033-4

Conflict of Interest Statement: The authors declare that the research was conducted in the absence of any commercial or financial relationships that could be construed as a potential conflict of interest.

Copyright $\odot 2015$ Zhao, Liu, Guo and Zhu. This is an open-access article distributed under the terms of the Creative Commons Attribution License (CC BY). The use, distribution or reproduction in other forums is permitted, provided the original author(s) or licensor are credited and that the original publication in this journal is cited, in accordance with accepted academic practice. No use, distribution or reproduction is permitted which does not comply with these terms. 